\title{
RELATIONSHIP BETWEEN ORGANIZATIONAL DESIGN AND INNOVATION PROCESSES IN SERBIAN PUBLIC COMPANIES
}

PhD Borislav Kolarić, "Telecom Serbia"a.d. Belgrade, IJ Sremska Mitrovica, Serbia

\begin{abstract}
In business environment that changes rapidly, innovation becomes a precondition for success and even the survival of some organization. Therefore, innovation finds the way and takes most important place in many organizations throughout the world. Innovation brings development and growth of a company, creation of opportunities in new markets and, at the same time, injects new life to mature industries. Aware of this fact, many organizations aim at launching new products and services through continuous innovations and thus remain successful in the market. That is also followed by the requirement for changing the traditional way of doing business, which implies the increase of interest in mechanisms that are implied by modern management principles, such as knowledge management and innovation processes. The purpose of the paper presented consisted in studying and identifying the extent to which the processes of innovation are applied in Serbian public enterprises.
\end{abstract}

Key words: innovation, innovative processes, organizational design

\section{Introduction}

As business world becomes increasingly complex and competitive, many companies turn to innovation as one of the relevant and permanent sources of competitive advantage. Most companies, regardless of their size, are actively involved in the search for finding the ways to be more innovative. While some companies have well-defined and developed processes of production and service providing, the others are mastering the creation and management of the ideas related to innovation. The necessity of innovation is largely accepted and most leaders know that being successful in a longer period of time implies the development of innovative processes within the organization.

In literature, we can find many types of innovations, which is a consequence of different ways of determining their distinctions. Most frequently cited distinction is between innovations of products and processes (Boer \&
During, 2001) which can further be divided according to the level of novelty that they include, which is a classical dichotomy into radical and incremental innovations (O'Reilly \&Tushman, 2004). Main difference in the form between these two types of innovations is in the degree of knowledge and skills included in innovations. Incremental innovations refer to specialized knowledge and skills of employees in one filed, while radical innovations are related to wide and general knowledge and skills of employees that can be used in various fields (Kang \& Snell, 2009). In order to create new products, services or processes, the organization needs to reallocate its existing resources and combine new and old resources in a new way. Innovations require different expenditures of funds and combination of practice, which makes a source for exchange and cooperation (Tsai \& Ghoshal, 1998). Ability of an organization to innovate makes a precondition for successful use of inventive resources and new technologies. Generally speaking, the term of organizational innovation refers to the creation or adoption of an idea or new organizational behaviour (Damanpour, 1996). Organizations that have achieved such a level of culture possess the capacity for the creation of all types of innovation starting with incremental, through inspiring, and all the way to the radical that generate new ways of doing business.

Choice and dealing with problems on the title topic are initiated by today's manner and quality of providing services by public companies in Serbia. Within most public services and enterprises, the inefficiency is manifested. Uniform policy within all parts of the organization is evident, high level of centralization and lack of the need for adapting to users' needs. As opposed to that, liberalization and deregularization of the market have enhanced the emergence of new operators and distributors in the fields in which Serbian public companies 
were still monopolists and still have a dominant role. In order to survive and be efficient in newlyemerged environment, these companies need to turn to contemporary ways of doing business, i.e. contemporary marketing and management principles. Pursuant to the aforesaid, the purpose of the paper and subject research consisted in identification of the efficiency of applying innovation processes in Serbian public companies.

\section{Literature review}

Innovation can be understood as the process of learning and knowledge creation through the definition of new problems and knowledge developed through its solving. Main issue implies a problem of finding a way to translate individual insights into collective knowledge and organizational abilities in an organization. Although some researchers claim that learning is essential through individual activities, most theories of organizational learning stress the importance of collective knowledge as a source of organizational abilities (Grant, 1996).

Anand's (2007) studies have dealt with problems of generation and incorporation of elements for supporting knowledge and innovations in organizational structure. $\mathrm{He}$ believes that presence of various competences, continuous development of new knowledge, as well as organizational support through available resources, they are crucial elements for creating a structure that is science and innovation-friendly. In addition, the same expert believes that construction and use of internal network, practices exchange, as well as construction of external network with buyers and market is a great benefit and help in the creation of innovative structure (Anand et al, 2001)

Froehle (2000) stresses the importance of the participation of people from different functions or different professions in innovation process, and Avlonitis (2001) sees multifunctional participation as an important factor in innovative processes. The reason for including the people from various functions or various professions is in the fact that they bring different knowledge and skills, which facilitates creativity, learning and development of knowledge necessary for innovations (Avlonitis, 2001).The abovementioned is supported by the research of Fay (2006), who found that multidisciplinary nature has a positive impact on quality of team innovation, creating good team processes in them.

Teams and working group are very significant in the aspect of their ability for encouragement and support of innovations. It is important to stress that the creation of successful working groups is not always the same. They will be innovative when are able to integrate the people with different standpoints allowing them a free exchange of ideas and experiences (McLean, 2005). Multifunctional teams can be especially good in the creation of a new idea that is innovative and practical. These teams bring about different skills and knowledge, and thus the approach to the problems from various perspectives, which creates the possibility to offer a great number of creative solutions to the problem (Glover \& Smethurst, 2003).

Therefore, multi-functional teams have the necessity for diversity of opinions, perspectives and cultural heritage, i.e. it is essential that no "clones" are made from their members [30]. However, creating the teams of people from different backgrounds, origin, knowledge and skills may include conflicts and it is very important to know how to deal with them, so that the conflicts always take place in positive constructive context (Glover \& Smethurst, 2003).

Confidence among employees is a significant part of the success of innovation processes and knowledge management in the company. Building confidence between employees and managers, as well as between employees is a means for success of innovation processes (Phillips, 1997). Cook and Wall (1980) conclude that the confidence between individuals and groups in organization is very important and significant for long-term stability of organization and welfare of its members. According to De Furia (1997), benefits that an organization may have from high level of confidence involves: stimulation of innovations, moving towards high emotional stability, facilitation of acceptance and 
openness for free expression, encouragement of risk acceptance.

Organization needs to develop open environment in which the employees feel free to share their ideas and knowledge and use the knowledge of others in the atmosphere of confidence. Building the confidence between employees, as well as in the relation of employees and managers, represents a tool for the success of the process of innovation creation.

Truly creative culture tends to be different through the open communication and free exchange of ideas. That includes the communication between various parts of organization, between various team members, as well as the communication of various levels within organizational hierarchy. Communication does not only include the exchange of ideas, but also the exchange of learned experiences from successful and unsuccessful activities. One way to improve the communication implies more encounters, more contemporary on-line tools for knowledge exchange, multifunctional tasks and more brainstorming tasks (McLean, 2005).

It is very important to include the employees in the process of developing new services. Experiences that are acquired during interactions with users can be significant support in the creation of innovations, especially because they are related to information about services that users consider valuable.

De Brentani (2001) has identified the engagement of employees in innovation process as one of the factors of success that influence the final outcome of those processes. Such strategy should contribute to the creation of the alignment between innovation and users' needs. However, Ramirez (2004) claims that involvement of employees in innovation processes, in many cases implies the breaking of institutional authority of the structure. For that reason, involvement of employees in innovation processes can be a challenge for organization and specificity for management that needs to be prepare for ceding some of its formal powers.

Sonesson (2007) indicates that one of the contributions on the quality of services innovation occurs by participation of employees from the front sales line, through their managing the processes with buyers, as well as creation of friendly relations and confidence. He concludes that service innovations can benefit from the involvement of employees from the front sales line, but stresses that their participation in innovation processes must be supported by the managers that need to allocate time and resources for the employees that participate in development process.

\section{Research methodology}

\subsection{Goal and tasks of the research}

In accordance with theoretical framework about significance of innovation processes in modern business and having in mind current position of public enterprises in Serbia in their business environment, the goal of the research was to examine to what extent is the attention in these companies paid in application of modern management tools.

Thus conceived, the goal of the research was focused on a several tasks:

- Identification of employees' opinion regarding confidence and ideas exchange within the company.

- Determination of the relationship of the management towards innovation processes.

- Determination of the level of encouraging the cooperation and teamwork from the part of the management.

- Determination of the level of involvement employees towards business processes.

\subsection{Sample, research method and applied statistical data processing method}

Sample of respondents consisted of employees in public companies in the territory of the Vojvodina region. Research has included 150 respondents from 3 dominant public enterprises: "Pošta Srbije", "Elektrodistribucija", "Telekom Srbija". As the most optimal instrument for subject research, the questionnaire was used. Answers in the questionnaire were of closed type and designed on the basis of Likert scale, so that 
the respondent could choose one out of five answers offered for each question. Testing the validity of questionnaire, as well as the results obtained, was realized through many analyses and processing of data.

\section{Research results}

Analysis of the possibility of presenting and exchanging new ideas, as well as examination of the extent to which enterprise's management is aware of the significance of creative and innovations, had the task to collect necessary information and create realistic image about the extent to which current organization design in public companies in Serbia is suitable for the possibility of generating innovation processes.

\subsection{Exchange ideas and information's}

For the success of the innovation process, the climate of openness, trust and cooperation among the employees is of crucial significance. It is necessary that the employees feel free, that they have no fear that sharing their ideas will bring them to a worse business position.

Research results have shown that $67 \%$ employees believe that ideas and information exchange among the employees is present in a small extent, $24 \%$ believes that it does not exist at all, while $9 \%$ experience ideas exchange at a satisfactory level (Figure 1.):

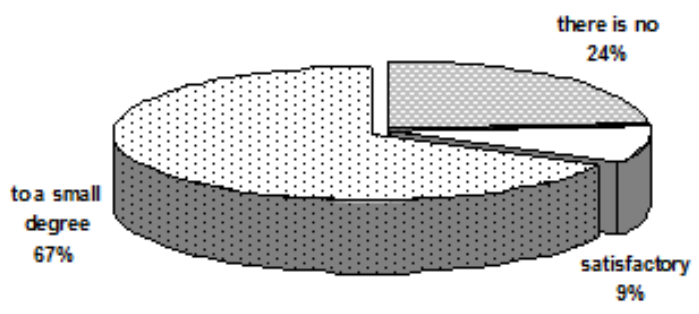

Figure1. Level of ideas exchange

It was also significant to analyze the data regarding the persons with whom the employees are willing to share their information and ideas. The result of research presented show that $22 \%$ of respondents have confidence and practice the ideas exchange with all colleagues within the company. The greatest number (47\%) has confidence in close colleagues only, while $31 \%$ respondents share their knowledge with colleagues from their service or department.

\subsection{Evaluation of innovations by company's management}

Some organization is successful if good individuals in it are successful. Today's modern and professional workers are not labour, they are capital that is productive and that creates additional value for its organization. As a creative and innovative part of each organization, people have the leading role in creation and maintenance of its competitive advantage.

When it comes to accepting and evaluating innovations from the part of management in enterprise, $64 \%$ respondents are completely dissatisfied with the existing treatment, $24 \%$ believes that they are evaluated partially, while $12 \%$ of employees have positive attitude and evaluation of the same (Figure 2.):

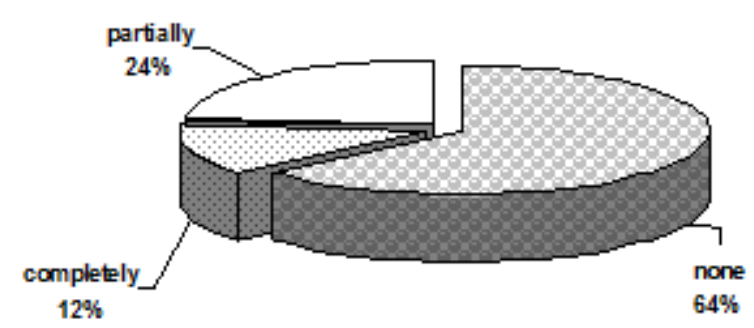

Figure 2: Evaluation of innovations

\subsection{Encouragement of cooperation and teamwork}

Cooperation and teamwork have a very important role in generation of innovations and new knowledge. More innovations come from the cooperation and community that through inventive thinking of individual mind.

Multifunctional teams can be particularly good in the creation of new idea that is innovative and practical. These teams bring various skills and knowledge, and thus also the approach to problems from various perspectives, which 
creates the possibility for offering a great number of creative solutions to the problem.

However, in the analysis of employees' attitudes regarding the quality of cooperation and existence of teamwork within the organization, it can be seen that only $12 \%$ of respondents believe that such relations exist in organization, while $39 \%$ do not have a positive opinion regarding the same question (Figure 3.).

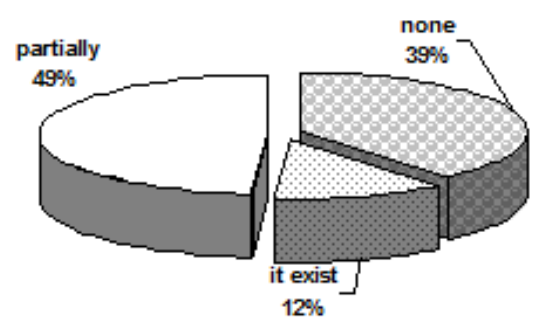

Figure 3: Existence of cooperation and teamwork

\subsection{Involving employees in business processes}

Today's modern and professional workers are not labour, they are capital that is productive and that creates additional value for its organization. As a creative and innovative part of each organization, people have the leading role in creation and maintenance of its competitive advantage. They wish to have an opportunity to show the management that they have abilities to assume responsibilities for the tasks assigned and to realize them with their creativity and teamwork.

When we speaking about involving employees in business processes, the research showed that $63 \%$ respondents are completely dissatisfied with the existing treatment, $23 \%$ believes that they are involved partially, while $14 \%$ of employees have positive attitude and evaluation of the same (Figure 4.):

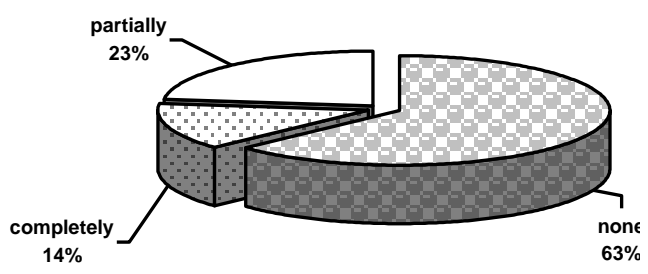

Figure 4: Involving employees in business processes

\section{Discussion}

Today, the organizations need to be prepared for new era that requires much efficient organizational design and encouraging management of innovations. Many studies have confirmed that organizations that take the challenge of management with modern management tools become more prestigious and successful in the market in relation to its competitors. Such organizations have greater possibilities for mobilization of knowledge, skills and experience of employees, and thus they become more capable for successful creation of new products and services in new ways that are faster, better and cheaper. In modelling such an organization, it is necessary to pay great attention to organizational design and make it such that he become the generator of climate, in which innovation are welcome.

Literature overview has indicated the significance of organizational trust and high level of cooperation between the employees, in today's conditions of modern business. Organizational climate of trust allows the employees to express their ideas and feelings and common learning. Organization without trust can create an unfavorable position with people that will prevent them from learning. Development of trust occurs in situations where the individuals have freedom of expression in their daily tasks, without unnecessary control, monitoring and supervision. By analyzing the processed data, it can be seen that even $67 \%$ of respondents believes that ideas and information exchange within Serbian public services are present to a small degree. By further observation, it is seen that this poor exchange of knowledge occurs largely with colleague within department or service.

The quality levels of cooperation and teamwork are closely related to the level confidence and information exchange. Cooperation and teamwork have a very important role in generation of innovations. More innovations come from the cooperation and community that through inventive thinking of individual mind. Multifunctional teams can be particularly good in the creation of new idea that is innovative and practical. Results obtained by this question point out that $12 \%$ of respondents sees the quality of cooperation and teamwork as 
satisfactory, $49 \%$ of respondents believe that it is expressed to a partially degree, while $39 \%$ considers that cooperation level is low. The results mentioned are partially the consequence of the type of organizational structure, which favorite's classical hierarchical and centralized system.

Some organization is successful if good individuals in it are successful. As a creative and innovative part of each organization, people have the leading role in creation and maintenance of its competitive advantage. Research results related to the possibility of bringing new ideas within the organization showed that $64 \%$ of employees believe that there is no opportunity.

As a creative and innovative part of each organization, people have the leading role in creation and maintenance of its competitive advantage. They wish to have an opportunity to show the management that they have abilities to assume responsibilities for the tasks assigned and to realize them with their creativity and teamwork. However, the research showed that $63 \%$ respondents are completely dissatisfied with the existing treatment, while $23 \%$ believes that they are involved partially,

Processes results in subject research have pointed to deficiencies in elements of organizational design of public companies, which represent relevant factors for the success of innovation processes. Poor attention paying to innovations and their inadequate treatment from the part of enterprise's management, low level of confidence among the employees, poor attention to involving employees in business processes, as well as insufficient support to cooperation and teamwork, indicate that the significance of innovations is still not understood in the right way, and that there is not sufficient attention paid to it. The employees see their tasks as centralized directives, without a possibility of involving their individuality, creativity and autonomy. They are very dissatisfied by non-acceptance of their ideas, criticism and suggestions

Traditional corporative environment, with its hierarchical structure, will not support innovation processes, which are by far more superior in organizations that encourage autonomy, respect, confidence and self-control as opposed to strict supervisions, rigid business limitations and direct control. For the possibility of generating innovation processes within an organization, basic preconditions need to be met regarding the reduction of hierarchical structure and bureaucratic policy, giving great independence and responsibility to employees, strengthening the communication between various functional units and expanding the connectedness of employees throughout the company, generation and free knowledge exchange. At the same time, it is necessary to develop an open environment in which all employees, in atmosphere of confidence, feel free to share their knowledge and use the knowledge of other people.

In order for organizational design to be able to respond to all challenges of the concept of innovation processes, it is necessary to have a flatter hierarchical structure, which provides: high level of autonomy for individuals; respecting skills, knowledge and talents; reduction of bureaucratic behaviour; rewarding active knowledge sharing and creation of innovations; support to communication and coordination, both between individuals and between groups and teams, building the climate of confidence and respect. Managers need to be ready to leave certain controls based on traditional business model and facilitate the flow of knowledge through the creation of the environments of learning, research and sharing. Traditional corporate structure and environment need to be modernized to a knowledge-based structure and environment, so that those companies can survive and be profitable.

\section{Conclusion}

Literature suggests that processes of innovations today represent a significant factor of some organization, and as such they find their place in basic principles of modern business, regardless of the size or activity of organization.

Purpose of the paper at the title topic was reflected in examination to what extent is the application of innovation process in public companies in Serbia successful. Research, as well 
as the results obtained, point out to the deficiencies in elements of organizational design of public companies, which are relevant factors for the success of innovation processes. Low level of confidence among the employees, poor attention to innovations and involving employees in business processes, as well as insufficient support to cooperation and teamwork, point out to the fact that significance of innovations is still not understood in the right way, and that there is not sufficient attention paid to it.

Besides the awareness of the fact that concepts of knowledge management and innovation processes in Serbia are slightly known and applicable, top management of public enterprises in Serbia should seriously deal with current organizational structure and culture in its companies. Having in mind that these companies are in a market game where competitors become more powerful and stronger every day, it is necessary to incorporate modern business principles, which certainly exclude the concept of innovation processes.

In order for the programme of innovation processes to have an opportunity for successful implementation, one of the relevant preconditions is climate of confidence, openness, cooperation and mutual respect of employees throughout the organization. The employees need to be included in the business processes. At the same time, it is necessary to develop open environment in which the employees feel free to share their knowledge are use the knowledge of other people, in the atmosphere of confidence. Building confidence between employees is a means for success of innovation processes. The application of innovation processes requires the role of leaders from managers, which implies owning conceptual skills, emotional intelligence, ability for teamwork, ability for motivation and tendency to constant improvement of employees.

\section{REFERENCES}

1. Anand, N., Gardner, H.K., \& Morris, T. (2007). Knowledge-based innovation: emergence and embedding of new practice areas in management consulting firms. Academy of Management Journal, Vol.50, pp. 406-428.

2. Avlonitis, G.J., Papastathopoulou, P.G., \& Gounaris, S.P. (2001). An empirically-based typology of product innovativeness for new financial services: success and failure scenarios. Journal of Product Innovation Management, Vol. 18, pp. 324-342.

3. Boer, H., \& During W.E. (2001). Innovation, what innovation? A comparison between product, process and organizational innovation.

International Journal of Technology Management, Vol. 22, pp. 83-107.

4. Cook, J., \& Wall, T. (1980). New work attitude measures of trust, organizational commitment and personal need nonfulfillment. Journal of Occupational Psychology, 53.

5. Damanpour, F. (1996). Organizational Complexity and Innovation: Developing and Testing Multiple Contingency Models. Management Science, 42/5, pp. 693-716.

6. De Brentani, U. (2001). Innovative versus incremental new business services: different keys for achieving success. Journal of Product Innovation Management, Vol. 18, pp. 169-187.

7. De Furia, G.L. (1997). Facilitators Guide to the Imnterpersonal Trust Surveys. Pfeiffer\&Co.

8. Fay, D., Borrill, C., Amir, Z., Haward, R., \& West, M. A. (2006). Getting the most out of multidisciplinary teams: a multi-sample study of team innovation in health care. Journal of Occupational and Organizational Psychology, Vol. 79, pp. 553-567.

9. Froehle, C.M., Roth, A.V., \& Chase, R.B. (2000). Antecedents of new service development effectiveness. An exploratory examination of strategic operations choices. Journal of Service Research, Vol.3, pp.3-17.

10. Glover, C., \& Smethurst S. (2003). Great Ideas Wanted People Management Online, (April 8).

11. Grant, R.M. (1996). Toward a Knowledge-Based Theory of the Firm. Strategic Management Journal, 17, pp. 109-122.

12. Kang, S.C., \& Snell, S.A. (2009). Intellectual capital architectures and ambidextrous learning: A framework for human resource management. Journal of Management Studies, Vol. 46, pp. 6592.

13. McLean, L.D. (2005). Organizational Culture's Influence on Creativity and Innovation: A Review of the Literature and Implications for Human Resource Development. Advances in Developing Human Resources, 7 (May), pp. 226-246.

14. O'Reilly, C.A., \& Tushman, M.L.(2004). The ambidextrous organization. Harvard Business Review,pp. 74-81.

15. Phillips, C.J. (1997). Do you trust me?, Executive Excellence 14.

16. Ramirez, M. (2004). Innovation, network services and the restructuring of work organization in customer services. Service Industries Journal, Vol.24, pp. 99-115. 
17. Sonesson, O. (2007). Tjänsteutveckling med personalmedverkan. Karlstad university, Fakulteten för ekonomi, kommunikation och IT.

18. Tsai W., \& Ghoshal S. (1998). Social capital and value creation: The role of intrafirm networks. Academy of Management Journal, Vol. 41, No. 4, pp. 464-476. 